\title{
Nicolazzi, Fernando \\ Um estilo de História: \\ a viagem, a memória, o ensaio: sobre \\ Casa-grande \& senzala e a representação do passado
}

Maria Lúcia Garcia Pallares-Burke*

São Paulo: Ed. Unesp, 2011. 484p.

Tanto já se escreveu sobre Gilberto Freyre, e particularmente sobre Casa-grande \& senzala, que está cada vez mais difícil se dizer alguma coisa nova e significativa sobre o autor ou sobre o livro de 1933. O risco de "chover no molhado", como o próprio Nicolazzi diz, é bastante grande. Entre os estudiosos anteriores de Casa-grande, Nicolazzi está mais próximo de Ricardo Benzaquen, cujo trabalho reconhece como inspirador, mas oferece uma visão propriamente sua da obra de Freyre.

Um estilo de História é uma versão ligeiramente modificada de uma tese de doutorado defendida na Universidade Federal do Rio Grande do Sul (UFRGS) em 2008, que recebeu o prêmio Manoel Luiz Salgado Guimarães da Anpuh em 2010. Apesar de Nicolazzi não ter aproveitado esse lapso de 7 anos entre a defesa e a publicação de 2015 para fazer referência aos estudos publicados nesse intervalo, dá uma contribuição original para a montanha do que se pode chamar de "Estudos Freyreanos", examinando Casa-grande de vários ângulos. Como o próprio autor confessa logo no início, seu livro é "um conjunto de ensaios travestido em tese universitária”, o que é muito apropriado no caso do estudo de um autor que adorava o gênero ensaístico e descrevia até mesmo sua volumosa obra de novecentas e tantas páginas, Ordem e Progresso, como um "ensaio". O que mantém Um estilo de História mais ou menos coeso é o argumento do autor de que Freyre escolheu um estilo de representação do passado, um modo de proximidade, que diferia muito das representações anteriores empregadas por antigas histórias do Brasil; e que esse estilo pode ter mesmo sido adotado por Freyre em resposta direta a Os sertões.

\footnotetext{
* Research Associate, Centre of Latin American Studies, University of Cambridge. Cambridge, UK. mlp20@cam.ac.uk
} 
Para justificar sua tese sobre representações, Nicolazzi adota o método de leitura atenta (close reading) dos textos para chegar a conclusões sobre o estilo, as estratégias literárias e os modos de persuasão tanto de Euclides da Cunha quanto de Gilberto Freyre. Seus sete ensaios-capítulos são organizados em três seções. A primeira se inicia com um relato da recepção de Casa-grande no Brasil (em outras palavras, representações de uma representação), e daí se volta para os dez prefácios do autor, nos quais ele se defendia contra más representações de sua obra, ou deturpações, e conversava, por assim dizer, com seus resenhistas. A segunda seção, que compreende mais dois ensaios, deixa Freyre de lado para se concentrar em Euclides da Cunha. A terceira seção retorna a Freyre, com três capítulos dedicados respectivamente a viajantes, memórias e ao próprio gênero do ensaio. Nicolazzi considera Freyre um viajante que privilegiava o testemunho de outros viajantes e oferecia aos seus leitores a sensação de estarem viajando ou no espaço ou no tempo. Também enfatiza a importância das memórias em Casa-grande: as do próprio autor, as de sua família e as dos indivíduos que entrevistou, o mais famoso dos quais foi o ex-escravo Luiz Mulatinho. O livro termina com um ensaio sobre o ensaio, refletindo sobre ensaios históricos e sobre a tradição brasileira do ensaísmo, a fim de buscar a singularidade da contribuição de Freyre para essa tradição.

Um estilo de História é fruto de uma leitura vasta e variada, que inclui não somente a historiografia, de Heródoto a Hayden White, mas também filosofia, literatura, psicologia, sociologia e antropologia, os campos nos quais o próprio Freyre estava muito à vontade. Nas páginas de Nicolazzi, Paul Ricoeur está ao lado de Wolf Lepenies, Roland Barthes ao lado de Clifford Geertz, Oliver Sacks de Quentin Skinner, François Hartog de Walter Benjamin, Jean Starobinski de Frank Ankersmit, Michael Baxandall de Gérard Genette, além de outros. Enfim, tantos nomes, tantas luzes a iluminar um texto.

Assim como a justaposição do livro de Euclides com o de Sarmiento, Civilização e barbárie, se tornou um tópos, o mesmo aconteceu com a comparação e o contraste entre Os sertões e Casa-grande, que novamente coloca a representação do "outro" versus a representação de "nós" em pauta. No entanto, Nicolazzi desenvolve esse contraste de modo interessante e valioso, focalizando pontos de vista. Segundo ele, o contraste essencial entre Freyre e Euclides - cujo trabalho Freyre estudou cuidadosamente e sobre o qual escreveu mais de uma vez - é que Euclides exemplifica o que Claude Lévi-Strauss chamou de "olhar distante", observando e representando outra cultura como se estivesse pairando alto no ar; uma cultura que ele via como oposta à sua própria, ou seja, uma representando a civilização, e a outra, a barbárie. Sua estratégia literária 
era a do naturalista, registrando detalhes com o espírito de um cientista, uma espécie de Émile Zola do sertão. Em contraste, Freyre, como um antropólogo no campo, tentava chegar perto dos escravos e ainda mais perto dos senhores (e das senhoras) de engenho sobre os quais escreveu. Como Michelet - e diferentemente de Euclides - Freyre tentava evocar o passado, suprimir a distância e identificar-se com os mortos e com tudo o que já se foi. Ele pode até ser criticado - e o foi por Ricardo Benzaquen - por estar "correndo o risco de uma proximidade excessiva".

Há muito a ser dito em favor desse contraste. Afinal de contas, Freyre disse em certa ocasião que "o passado nunca foi, o passado continua". Sua "história íntima" e sua "história sensorial" tentavam exatamente tornar os leitores capazes de ver, ouvir, cheirar, sentir o gosto e até mesmo tocar o passado. $\mathrm{O}$ elemento autobiográfico em Casa-grande, enfatizado ainda mais em $1937 \mathrm{em}$ seu Nordeste, é efetivamente central, e a confusão entre a vida do autor, de sua família e de sua região natal (ilustrada pelo uso frequente que Freyre faz da primeira pessoa do plural) é, na verdade, reminiscente de Michelet.

No entanto, a oposição entre distância e proximidade precisa ser qualificada, se não mesmo questionada - do mesmo modo como o próprio Freyre gostava de primeiro estabelecer, para depois solapar as categorias opostas de sobrados e mocambos, ordem e progresso, e assim por diante. Pois Freyre não era adepto de polaridades rígidas - que não davam conta dos paradoxos, contradições e complexidades da realidade humana - e se apelava para oposições binárias, sua estratégia era sempre enfraquecê-las por meio de mediações entre opostos, para o que o uso de termos recorrentes como quase-, para-, semi- se adaptava muito bem.

Assim, no que diz respeito à proximidade que Freyre pretenderia ter de seu objeto de estudo, deve-se acrescentar que ele também era capaz de ver seu próprio país com olhos estrangeiros. Seu emprego recorrente de textos escritos por viajantes como evidência não somente dá aos leitores a sensação de "estarem lá”, como Nicolazzi sugere, mas também os provê com distanciamento, já que os viajantes são frequentemente estrangeiros que podem ver mais facilmente o que nativos não veem. De qualquer modo, em algumas de suas passagens menos memoráveis, Freyre escorrega de seu estilo usualmente vívido e subjetivo e cai, por assim dizer, numa linguagem acadêmica, objetiva, escrevendo no capítulo 1, por exemplo, que "por mais que Gregory insista em negar ao clima tropical a tendência para produzir per se sobre o europeu do Norte efeitos de degeneração ... grande é a massa de evidências que parecem favorecer o ponto de vista contrário". Aqui, como em outros pontos da obra, a 
proximidade e a subjetividade do estudo da sociedade patriarcal dão lugar ao distanciamento e à objetividade. Pode-se, pois, descrever Casa-grande muito apropriadamente como um livro híbrido, não somente no sentido de combinar técnicas científicas e de ficção, como Nicolazzi aponta, mas também por se mover entre o fora e o dentro, entre distância e proximidade.

Como uma boa tese de doutorado, Um estilo de História é extremamente minuciosa e, em certos aspectos, ainda "cheira" a uma tese no sentido de que o autor não parece saber bem quando parar, repetindo argumentos e mesmo citações (uma delas três vezes) a fim de fortalecer seu argumento. Os leitores, ou ao menos alguns deles, podem ter às vezes a sensação de que Nicolazzi está usando uma marreta para abrir uma noz. Como muitas teses brasileiras, Um estilo de História está também sobrecarregada de reflexões sobre método e teoria, assim como apoiada em grande bagagem intelectual, desconsiderando, às vezes, o princípio conhecido como "o rifle de Chekhov". Chekhov certa vez aconselhou os escritores a "removerem tudo que não tem relevância para a estória. Se você diz no capítulo primeiro que tem um rifle pendurado na parede, no segundo ou no terceiro esse rifle tem necessariamente de ser usado para atirar em alguma coisa. Se não for para ser disparado, então o rifle não deveria estar pendurado lá". Do mesmo modo, se a Metahistory de Hayden White é discutida na introdução, como foi o caso, os leitores seguramente têm o direito de esperar que o livro de White seja usado mais tarde, discutindo, por exemplo, se Casa-grande \& senzala foi "encenada" como uma comédia ou romance. Essas expectativas, no entanto, são frustradas.

Outra questão que importa levantar diz respeito ao uso acrítico que Nicolazzi fez, algumas vezes, dos escritos autobiográficos de Freyre, especialmente de seu "diário da juventude". Esse texto ocupa lugar importante no livro para reforçar seu argumento sobre a legitimidade que as experiências vividas por Freyre dão ao estilo de história que escolheu escrever. Há evidências de que esse diário "da juventude", publicado em 1975, não foi efetivamente redigido entre 1915 e 1930, tal como o Freyre maduro - tão envolvido em self-fashioning - quis fazer crer. Ele era, na verdade, exímio na arte da autoapresentação, produzindo com esmero a imagem que os leitores deveriam ter dele. Nicolazzi reconhece isso logo na primeira parte de seu livro. No entanto, várias vezes utilizará esse "diário", ou ensaio-memória, como se ele representasse fielmente o que o autor fizera ou pensara quando ainda estava para escrever Casa-grande. É de se crer que esses deslizes se devam ao fato de o livro incluir textos escritos em momentos diversos, e que falhas ou descuidos como esses compreensivelmente escaparam na revisão. 
Não obstante esses pequenos senões, Um estilo de História élivro inovador e perspicaz que elucida, inspira e instiga a curiosidade do leitor. É também valioso por tratar de ideias de proximidade e distância nos moldes de alguns estudos recentes e refinados sobre "distância histórica", em especial os desenvolvidos por Mark Phillips e alguns de seus colegas. Particularmente interessante é a diferenciação que Phillips faz entre distância e distanciamento, o primeiro uma postura espontânea entre os historiadores, o segundo uma estratégia proposital usada por alguns deles para trazer o passado para perto do leitor, como num close-up, quando assim acham importante, ou distanciar o passado para obter outros efeitos. Enfim, a retórica da proximidade e da distância como uma ferramenta que alguns historiadores usam conscientemente, como um romancista, para causar determinados efeitos em seus leitores, é uma linha de estudos fecunda à qual o livro de Nicolazzi pode ser associado. E, nesse sentido, Um estilo de História tem o grande mérito de potencialmente acenar para um novo e promissor fio a ser seguido pelos estudiosos de historiografia e de Gilberto Freyre.

Resenha recebida em 10 de março de 2016. Aprovada em 21 de março de 2016. 